\title{
PENERAPAN KAMUS KALIMAT BAHASA BALI UNTUK WISATAWAN
}

Ayu Aprilyana Kusuma Dewi

Email: aprilyana.beklencipss15@gmail.com

Politeknik Bintan Cakrawala

\begin{abstract}
The application of Natural Language Processing (NLP) in the Balinese sentence dictionary is an application that can provide information about the meaning of Indonesian to Balinese translation using the words contained in the Indonesian pocket dictionary, the results or meanings obtained are based on the application of Natural Language Processing (NLP) in accordance with the stipulated provisions. This application does not translate per word but per sentence. The application of NLP in the Balinese sentence dictionary serves to provide convenience for tourists or users who are used to communicate with the Balinese people and understand the Balinese language itself. In addition, it can provide time efficiency to users because this application is built offline on the Android mobile operating system, so that it can be accessed anywhere and anytime. In its implementation, the waterfall method is used and the output of this application is Indonesian sentences to Balinese sentences. And in the development of this application used tools with UML (Unified Modelling Processing) which consists of use case diagrams, activity diagrams, sequential diagrams, statechart diagrams and class diagrams.
\end{abstract}

Keywords: Dictionary, Natural Language Processing (NLP), Balinese

\section{Abstrak}

Penerapan Natural Language Processing (NLP) pada kamus kalimat Bahasa Bali merupakan aplikasi yang dapat memberikan informasi tentang arti terjemahan Bahasa Indonesia ke Bahasa Bali dengan menggunakan kata-kata yang terdapat pada pocket dictionary Bahasa Indonesia, hasil atau arti yang didapatkan berdasarkan penerapan Natural Languange Processing (NLP) sesuai dengan ketentuan yang ditentukan pada salah satu model kecerdasan buatan. Pada aplikasi ini tidak menerjemahkan per kata tetapi per kalimat. Penerapan NLP pada kamus kalimat Bahasa Bali berfungsi untuk memberikan kemudahan untuk wisatawan atau pengguna aplikasi kamus yang digunakan untuk berkomunikasi dengan masyarakat Bali dan memahami tentang Bahasa Bali itu sendiri. Selain itu dapat memberikan efisiensi waktu kepada 
pengguna karena aplikasi ini dibangun secara offline pada sistem operasi handphone android, hingga dapat diakses dimana dan kapan pun. Dalam pelaksanaannya digunakan metode waterfall dan output dari aplikasi ini adalah kalimat Bahasa Indonesia ke kalimat Bahasa Bali. Dalam pembangunan aplikasi ini digunakan alat bantu dengan UML (Unified Modelling Processing) yang terdiri dari use case diagram, activity diagram, sequensial diagram, statechart diagram dan class diagram.

Kata Kunci: Kamus, Natural Language Processing (NLP), Bahasa Bali

\section{Pendahuluan}

Bahasa Indonesia memiliki banyak suku yang beragam, setiap suku memiliki adat istiadat dan budaya yang berbeda-beda. Dari Masingmasing suku memiliki bahasa daerah yang berbeda untuk dapat berkomunikasi dan berinteraksi dengan masyarakat dan lingkungan sekitarnya. Salah satu budaya yang menjadi komoditas pariwisata di Indonesia adalah budaya Bali, dimana Pulau Bali merupakan pusat pariwisata di Indonesia dengan jumlah pendatang yang sangatlah banyak. Bahasa Bali memiliki karateristik yang sedikit berbeda dengan Bahasa Indonesia yaitu adanya karma atau tingkatan bahasa yang tidak mudah dipahami. Keberadaan Bahasa Bali sekarang ini sudah sering digunakan dalam kehidupan sehari-hari dengan masyarakat setempat. Dimana terlihat kemajuan teknologi yang sangat pesat saat ini maka dengan adanya sebuah aplikasi yang dapat mengakomodir keperluan pengguna dalam hal mencari pengganti buku yang dapat dibawa dengan mudah serta digunakan kapanpun dan dimanapun dengan efektif. Aplikasi yang dibutuhkan untuk dapat memenuhi kebutuhan pengguna tersebut adalah sebuah aplikasi kamus yang dapat menerjemahkan Bahasa Indonesia ke Bahasa Bali yang berbasis Android. Pada aplikasi kamus bahasa bali ini menyediakan informasi ilmu pengetahuan tentang kalimat dari Bahasa Indonesia diterjemahkan kedalam Bahasa Bali. Faktor yang menjadi kelebihan kamus pada perangkat seluler yaitu menjadi lebih praktis dan mudah 
dikarenakan dapat menerima informasi dengan cepat serta tidak terdapat batasan ruang dan waktu. Selain itu kamus memiliki kelebihan lain yang dapat memberikan informasi serta dapat dijadikan sebagai media pembelajaran untuk memahami istilah dan arti kata dari Bahasa Indonesia ke Bahasa Bali, sehingga dapat menambah ilmu dan wawasan bagi pengguna.

Penerjemahan kalimat Bahasa Indonesia ke Bahasa Bali ini menggunakan Natural Language Processing (NLP) dengan cara menerjemahkan sebuah kata yang akan dikembalikan lagi menjadi sebuah kalimat dengan arti yang baru. Proses ini mengubah sebuah kalimat Bahasa Indonesia ke Bahasa Bali sehingga akan membantu wisatawan domestik untuk berkomunikasi dengan masyarakat Bali.

\section{Konsep dan Teori}

\subsection{Kamus}

Kamus berisi kumpulan istilah dan berbagai macam nama yang disusun beserta penjelasan pemakaian serta keterangan makna/terjemahan. Sedangkan dalam Kamus Besar Bahasa Indonesia Daring, istilah kamus mempunyai arti buku acuan yang memuat kata dan ungkapan, biasanya disusun menurut abjad berikut tentang makna, pemakaian atau terjemahan. Kamus merupakan buku acuan yang memuat banyak makna. Kamus diurutkan berdasarkan abjad dari A-Z yang mempunyai tujuan untuk memudahkan pengguna dalam mencari istilah yang diinginkannya dengan cepat dan mudah. Kegunaan dari kamus ini dapat mempermudah pengguna dalam mencari istilah yang belum dipahami penjelasan maknanya. Digital itu sendiri merupakan sistem elektronik yang menggunakan signal digital yang mempunyai sifat putus-putus. Sedangkan untuk kamus digital memiliki kesamaan dengan kamus konvensional hanya memiliki kelebihan dalam pemakaiannya yang menggunakan sistem elektronik. Selain itu 
dalam penggunaannya kamus digital tidak perlu melakukan pencarian satu per satu kata akan tetapi hanya dengan mengetikan kata yang dicari secara langsung akan diolah untuk memeriksa ejaan dan menampilkan arti/penjelasan maknanya. Dinegara-negara maju, pengguna fasilitas pengolah kata elektronik sangat umum, sehingga menjadi salah satu indikator pemilihan terhadap pengolahan kata yang hendak dipakai (Rinarozky, 2007).

\subsection{Natural Language Processing (NLP)}

NLP merupakan studi tentang:

1. Manusia mengambil informasi dari dunia sekitar melalui interkasi dan stimulus. Hasilnya, yakni sensing melalui apa yang dilihat, dengan dan rasakan diolah oleh cortex dengan neuro-transmiter-nya, mengubah menjadi informasi yang disimpan dipikiran. Apa yang telah dicatata dan disimpan biasa disebut dengan representasi internal.

2. Representasikan itu dapat dipahami oleh dirinya. Apabila terdapat pada tingkat pemahaman sangat subjektif, maka dapat dikatakan sebagai subjective experience, tingkatan yang memiliki sifat berbedabeda tergantung pada tingkat pendidikan, kepercayaan/keyakinan dan nilai subjektif lainnya

3. Pemahaman itu atau bagaimana apa yang direpresentasikan ke dalam pikiran itu menjadi lebih bermanfaat untuk dirinya dan oranglain.

\subsection{Bahasa Bali}

Bahasa Bali merupakan sebuah bahasa Austronesia dari cabang Sundik yang lebih spesifik dari anak cabang Bali-Sasak. Bahasa ini dipertuturkan di pulau Bali, pulau Lombok bagian barat dan sedikit di ujung timur pulau Jawa. Bahasa Bali sendiri memiliki tingkatan dalam penggunaannya, diantaranya Bahasa Bali Kasar, Bahasa Bali Halus dan 
Bahasa Bali Madya. Bahasa Bali Kasar biasa dipergunakan untuk bertutur kata oleh kaum sudra atau digunakan oleh bangsawan dengan abdi dalemnya, sedangkan untuk Bahasa Bali Alus dipergunakan saat bertutur kata secara formal sebagai contoh dalam pertemuan tingkat desa adat atau dapat dipergunakan saat orang berkasta rendah berbicara dengan orang yang berkasta tinggi. Terakhir untuk tingkatan Bahasa Bali Madya dapat digunakan oleh masyarakat menengah pada saat pejabat berkomunikasi dengan bawahannya. Di Lombok Bahasa Bali terutama dipertuturkan di sekitar kota Mataram. Di pulau Jawa Bahasa Bali terutama dipertuturkan di beberapa daerah di kabupaten Banyuwangi. Bahasa Osing merupakan dialek khas yang dimiliki oleh Kabupaten Banyuwangi, yang dalam setiap kata-katanya terdapat penyerapan dari Bahasa Bali sebagai salah satu contoh pada kata "tidak" yang dalam Bahasa Bali dan Bahasa Osing samasama memakai kata "tusing". Bahasa Bali memiliki variasi yang cukup rumit dikarenakan telah ditentukannya sor-singgih oleh pembicara, lawan bicara dan hal lainnya yang dibicarakan. Secara umum, variasi dapat dibedakan antara temporal, regional dan sosial.

\section{Metode}

Metode yang digunakan pada pelaksanaan dan pembuatan Aplikasi Penerapan Natural Language Processing (NLP) pada Kamus Bahasa Bali adalah metode waterfall menurut Sommerville (2001). Adapun fase-fase yang ada didalam metode tersebut dijelaskan pada gambar dibawah ini. 


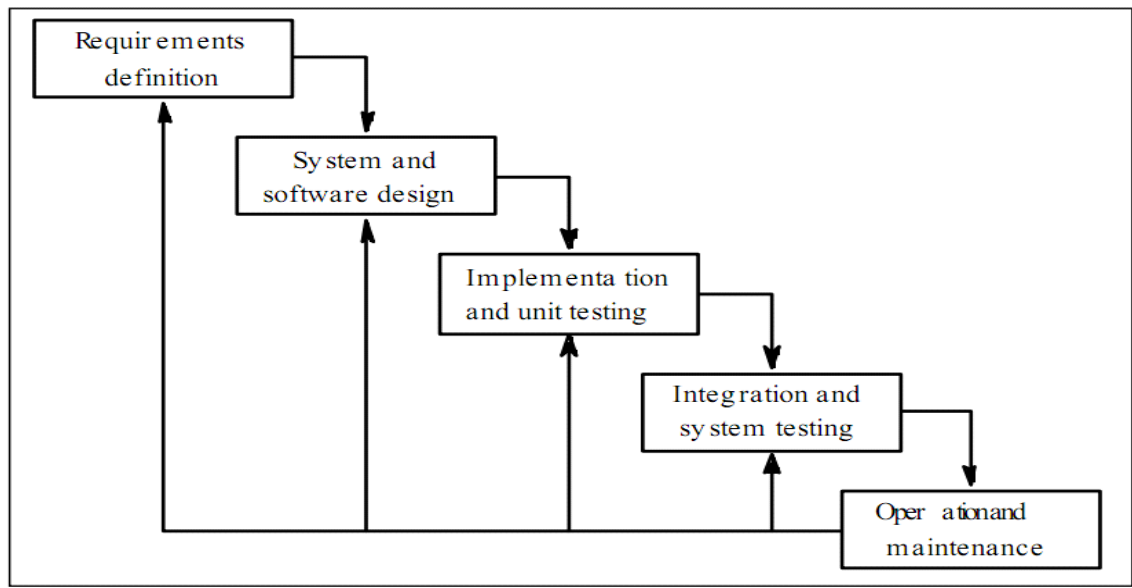

Gambar 1. Metode Waterfall Menurut Sommerville (2001)

Penjelasan pada masing-masing tahap adalah sebagai berikut:

a. Requirements Definition

Tahap ini merupakan proses pengumpulan kebutuhan lengkap yang kemudian akan dianalisis dan didefinisikan sesuai kebutuhan untuk merancang program/aplikasi yang akan dibangun. Dalam tahap ini diharapkan menghasilkan desain yang lebih sehingga dapat pengumpulan dan pengerjaannya diharuskan benar dan lengkap agar tidak terdapat kekurangan serta kesalahan. Pencarian data pelengkap kebutuhan sistem dilakukan dengan melakukan observasi dan interview pada instansi/orang terkait. Observasi dilakukan dengan melakukan pencatatan terhadap semua objek yang terlibat dalam pengembangan sistem. Dalam tahap ini, dilakukan observasi di Fakultas Sastra Bahasa Bali juga Fakultas Sastra dan Budaya Universitas Udayana serta pengumpulan data-data berupa kosakata Bahasa Bali dan Bahasa Indonesia.

b. System and Software Design

Desain dikerjakan setelah kebutuhan selesai dikumpulkan secara lengkap. Pada proses ini akan dilakukan pembuatan desain sistem yang akan digunakan, meliputi desain alur sistem, termasuk desain basis data 
dan desain dari tampilan (interface) yang akan dikerjakan. Desain alur sistem yang akan digunakan adalah Unified Modelling Language (UML). Adapun diagram yang akan dipakai antara lain: use case diagram, class diagram, sequence diagram, activity diagram dan statechart diagram. Terdapat juga desain form yang merupakan desain dari tampilan program. Desain yang diaplikasikan harus sesuai dengan desain alur sistem yang telah dibuat dan desain dari tampilan dibuat untuk memudahkan pengguna dalam penggunaan aplikasi sistem yang telah dibuat.

c. Implementation and Unit Testing

Tahap implementation and unit testing merupakan tahap pemrograman. Perancangan perangkat lunak dibangun dengan pemecahan/pembagian menjadi modul yang lebih kecil agar dapat digabungkan menjadi modul besar pada tahap berikutnya. Disamping itu, pada tahap ini pula dilakukan pengujian dan pemeriksaan terhadap fungsi dari masing-masing modul yang telah dibagi dan dirancang, telah memenuhi kriteria yang diinginkan atau belum.

\section{d. Integration and System Testing}

Unit program yang terintegrasi menjadi sebuah kesatuan sistem yang kemudian dilakukan pengujian. Dengan kata lain, tahap pengujian dapat ditujukan untuk menguji keterhubungan setiap fungsi perangkat lunak agar dapat menjamin bahwa persyaratan sistem telah dipenuhi. Setelah pengujian pada sistem telah selesai dilakukan, perangkat lunak akan dikirimkan kepada user bersangkutan.

\section{e. Operational Maintenance}

Tahap ini biasanya memerlukan waktu yang paling lama. Sistem diterapkan (di-install) dan dipakai. Pemeliharaan yang dilaksanakan yaitu pada tahap pengkoreksian dari beberapa kesalahan yang tidak ditemuka/terlewatkan pada tahap sebelumnya, perbaikan atas 
implementasi dan pengembangan pelayanan sistem sementara sebagai persyaratan baru untuk penambahan.

\section{Hasil dan Pembahasan}

\subsection{Requirement and Definition}

Pada tahap ini dilakukan pengumpulan kebutuhan yang terkait dengan sistem yang dibangun. Pada tahap dilakukan pengumpulan data yang selengkap-lengkapnya agar tidak mempengaruhi tahap yang lainnya. Hal yang dilakukan pada tahap ini adalah pengumpulan data berupa kosakata dalam Bahasa Indonesia dan Bahasa Bali. Data kosakata yang akan dimasukkan dalam aplikasi kamus ini. Kosakata yang dimasukkan kedalam kamus adalah kosakata yang sering umum dipakai dalam percakapan sehari-hari. Data kosakata yang digunakan dalam aplikasi ini, yaitu:

Tabel 1. Contoh Kosakata Bahasa Indonesia - Bahasa Bali dengan Kategori Subjek

\begin{tabular}{|c|c|c|c|}
\hline No & Kata Indonesia & Kata Bali Madya & Kata Bali Alus \\
\hline 1 & Saya & Tiang & Titiang \\
\hline 2 & Kamu & Ragane & Ratu \\
\hline 3 & Ibu & Biang & Ratu Biang \\
\hline 4 & Bapak & Aji & Ratu Aji \\
\hline 5 & Adik & Adi & Ari \\
\hline
\end{tabular}

Tabel 2. Contoh Kosakata Bahasa Indonesia - Bahasa Bali dengan Kategori Predikat

\begin{tabular}{|c|c|c|c|}
\hline No & Kata Indonesia & Kata Bali Madya & Kata Bali Alus \\
\hline 1 & Membeli & Numbas & Numbas \\
\hline 2 & Makan & Ngajeng & Ngrayunang \\
\hline 3 & Memakai & Ngangge & Igangge \\
\hline 4 & Bekerja & Karya & Pakarya \\
\hline 5 & Melihat & Cingakin & Nyaksinin \\
\hline
\end{tabular}


Tabel 3. Contoh Kosakata Bahasa Indonesia - Bahasa Bali dengan

Kategori Objek

\begin{tabular}{|c|c|c|c|}
\hline No & Kata Indonesia & Kata Bali Madya & Kata Bali Alus \\
\hline 1 & Meja & Meja & Meja \\
\hline 2 & Burung & Paksi & Paksi \\
\hline 3 & Buah-Buahan & Woh-Wohan & - \\
\hline 4 & Buku & Kitab & Buku \\
\hline 5 & Jam & Jam & Jam \\
\hline
\end{tabular}

Tabel 4. Contoh Kosakata Bahasa Indonesia - Bahasa Bali dengan Kategori Keterangan Tempat

\begin{tabular}{|c|c|c|c|}
\hline No & Kata Indonesia & Kata Bali Madya & Kata Bali Alus \\
\hline 1 & Di Rumah & Ring Jero & Ring Griya \\
\hline 2 & Dapur & Pwaregan & Pratengan \\
\hline 3 & Rumah & Puri & Geria \\
\hline 4 & Pura & Pemrajan & Parhiangan \\
\hline 5 & Kamar & Kamar & Kamar \\
\hline
\end{tabular}

Tabel 5. Contoh Kosakata Bahasa Indonesia - Bahasa Bali dengan Kategori Keterangan Waktu

\begin{tabular}{|c|c|c|c|}
\hline No & Kata Indonesia & Kata Bali Madya & Kata Bali Alus \\
\hline 1 & Malam & Wengi & Latri \\
\hline 2 & Besok & Bénjang & Bénjang \\
\hline 3 & Lusa & Malih Kalihraina & Malih Kalihraina \\
\hline 4 & Kemarin & Ibi & Dibi \\
\hline 5 & Hari & Raina & Raina \\
\hline
\end{tabular}

Selain itu dilakukan pengumpulan data berupa algoritma pencarian dan pengetahuan dalam membangun aplikasi Android. Pengumpulan data ini dilakukan dengan melihat buku dan referensi online guna mempermudah dalam pembuatan aplikasi kamus berbasis mobile ini. Kemudian dilakukan analisa terhadap data-data dan pendefinisian masalah yang terjadi. Masalah yang dihadapi adalah pemakaian kamus fisik untuk menerjemahkan kata memiliki waktu pencarian yang sedikit lama dan penggunaan kamus fisik kurang praktis untuk dibawa kemana-mana. Dalam sistem ini dibutuhkan data kosakata Bahasa Indonesia ke Bahasa Bali yang telah dipisah sesuai dengan kategori struktur kata Bahasa 
Indonesia. Pada sistem ini saat menginputkan kalimat dan memilih tingkatan Bahasa Bali yang diinginkan, maka sistem akan melakukan purnning. Prunning digunakan untuk mengeliminasi konektor yang tidak diperlukan pada kata dalam kalimat yang di-input-kan, setelah prunning selesai maka dilanjutkan dengan parsing kalimat. Parsing merupakan pemecahan kalimat menjadi kata sesuai dengan kategori struktur kata, bila parsing telah selesai akan dilakukan searching atau pencarian kode dari kata tersebut dalam dalam table kategori. Bila kode atau id ditemukan maka akan melanjutkan proses searching kedua untuk menerjemahkan kode tersebut kedalam tingkatan Bahasa Bali yang telah dipilih. Proses terakhir adalah penggabungan kata yang telah diterjemahkan menjadi kalimat.

\subsection{System and Software Design}

\section{Desain Sistem}

Desain sistem dibuat sesuai analisa yang dilakukan pada tahap pertama. Pembuatan desain sistem terdiri dari pembuatan usecase diagram, activity diagram, sequence diagram, class diagram dan statechart diagram. Desain sistem yang dibuat adalah desain usecase diagram menjelaskan tentang proses jalannya aplikasi kamus berbasis mobile adalah:
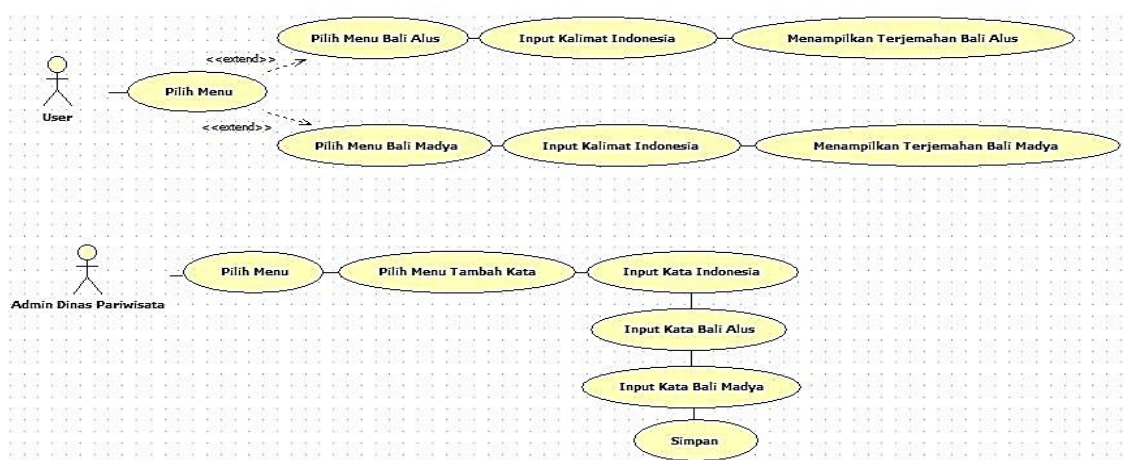

Gambar 2. Usecase Diagram Aplikasi Penerapan Natural Language

Processing (NLP) Pada Kamus Kalimat Bahasa Bali 


\section{Desain Database}

Database dibuat menggunakan bahasa SQL dalam SQLite. Terdapat 2 tabel untuk aplikasi kamus kalimat ini, yaitu table untuk table arti Bahasa Bali Alus dan arti Bahasa Bali Madya.

\subsection{Implementation and Unit Testing}

\section{Implementation Program}

Form ini digunakan sebagai form awal/form utama. Dalam form ini terdapat tombol Bahasa Bali Alus, Bahasa Bali Madya dan Tambah Kata yang berfungsi untuk memilih tingkatan bahasa serta menambahkan kata baru yang akan digunakan.

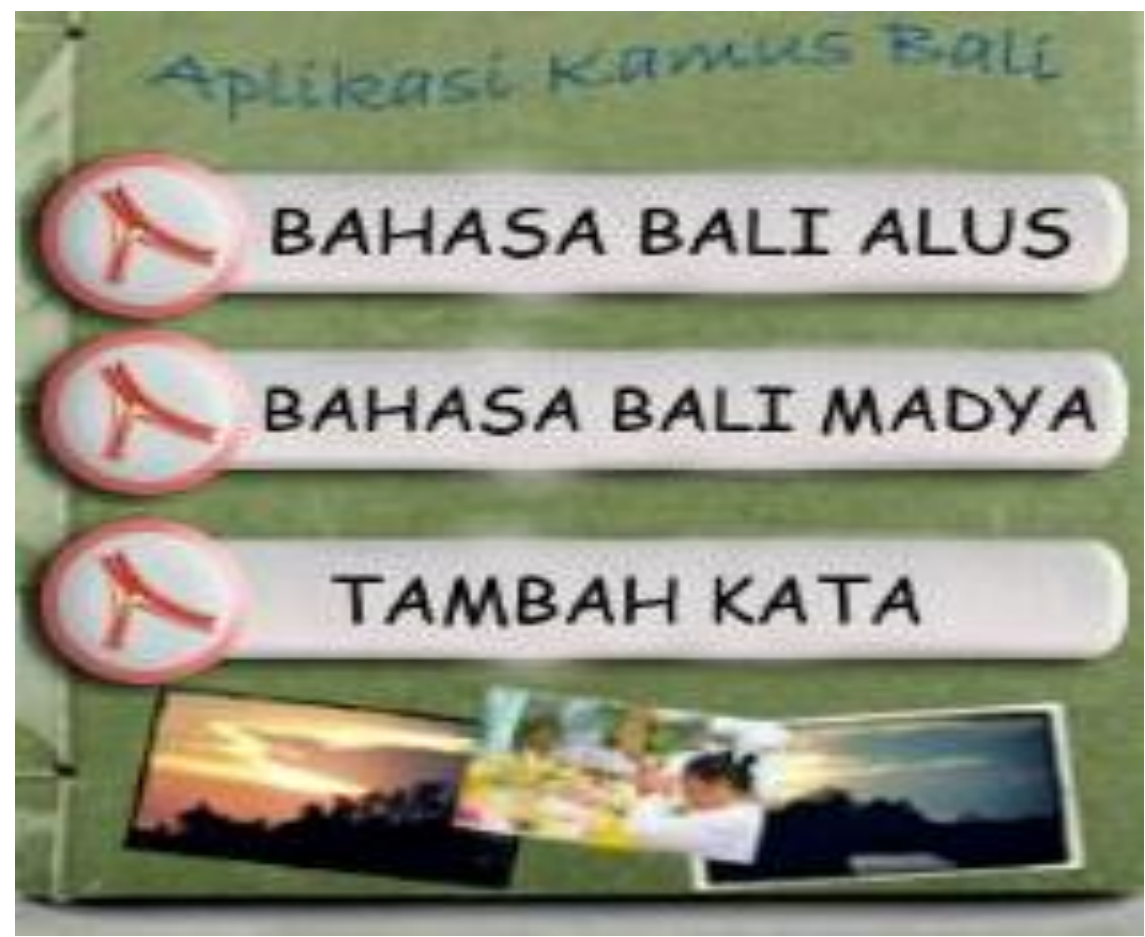

Gambar 3. Form Menu Utama Aplikasi Penerapan Natural Language Processing (NLP) Pada Kamus Kalimat Bahasa Bali

Form ini digunakan sebagai form menginputkan kalimat Bahasa Indonesia yang akan dicari arti kata ke dalam Bahasa Bali Madya. 


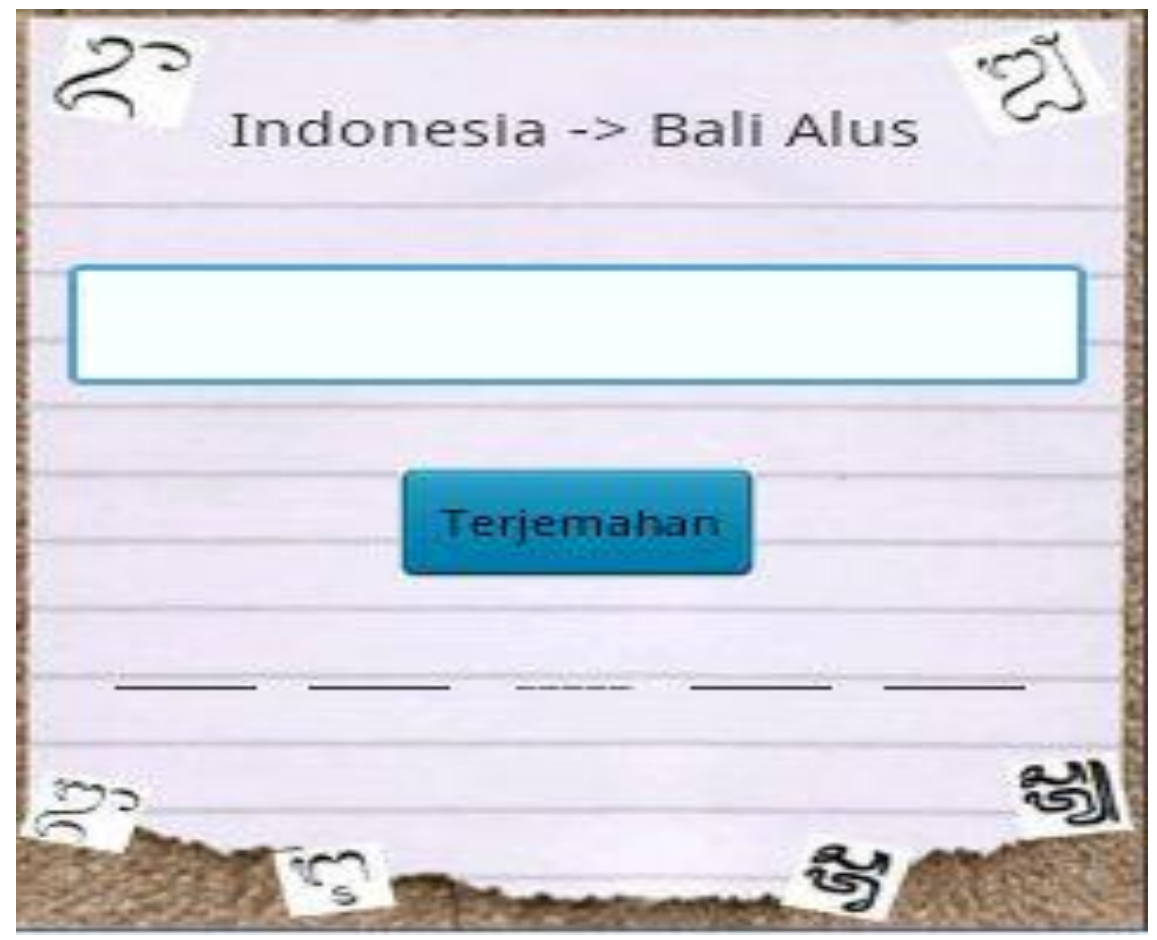

Gambar 4. Form Menu Bahasa Bali Alus Aplikasi Penerapan Natural Language Processing (NLP) Pada Kamus Kalimat Bahasa Bali

\section{Unit Testing}

Unit Testing merupakan tahap pengujian yang dilakukan dengan membuat perbandingan waktu manual dengan terkomputerisasi dan pengujian di mobile device bersistem Operasi Android untuk menguji sistem sudah sesuai dengan kebutuhan pengguna.

a. Perbandingan waktu manual dengan terkomputerisasi

Pengujian awal dilakukan dengan membandingkan waktu untuk proses pencarian antara menggunakan kamus fisik dengan aplikasi ini. Pada proses ini dilakukan oleh 3 user yang mencari terjemahan dari salah satu kata dan beberapa kalimat. Tabel perbandingan waktu untuk proses pencarian terjemahan secara manual dengan proses pencarian menggunakan program aplikasi adalah sebagai berikut: 
Tabel 6. Form Perbandingan Pencarian Terjemahan Secara Manual Dengan Menggunakan Aplikasi

\begin{tabular}{|c|l|c|c|}
\hline No. & \multicolumn{1}{|c|}{ Kategori } & $\begin{array}{c}\text { Manual } \\
\text { (Kamus Fisik) }\end{array}$ & Aplikasi \\
\hline 1. & $\begin{array}{l}\text { Proses pencarian } \\
\text { (kata 'saya') }\end{array}$ & 23 detik & 3 detik \\
\hline 2. & $\begin{array}{l}\text { Proses pencarian } \\
\text { (kalimat 'saya membaca } \\
\text { buku') }\end{array}$ & 5 detik \\
\hline 3. & $\begin{array}{l}\text { Proses pencarian } \\
\text { (kalimat 'saya membaca } \\
\text { buku di halaman') }\end{array}$ & 40 detik & 5 detik \\
\hline 4. & $\begin{array}{l}\text { Proses pencarian } \\
\text { (kalimat 'dimana alamat } \\
\text { rumah adik') }\end{array}$ & 30 detik & 5 detik \\
\hline
\end{tabular}

b. Perbandingan di mobile device dengan OS Android Pengujian selanjutnya dilakukan menggunakan perangkat seluler handphone Samsung dengan sistem informasi android (untuk semua versi sistem informasi android). Pengujian dilakukan dengan melibatkan user langsung dan user dapat mencoba aplikasi ini menggunakan perangkat seluler diatas. Dari hasil pengujian pada perangkat seluler dengan sistem operasi android, aplikasi berjalan dengan baik. Pilihan menu berfungsi dengan baik dan proses pencarian juga menghasilkan terjemahan yang sesuai. Berikut adalah form hasil uji coba dengan menggunakan perangkat seluler oleh user pengguna handphone dengan sistem operasi android:

Tabel 7. Form Pengujian Pada Perangkat Seluler

\begin{tabular}{|c|c|c|}
\hline No. & Kategori Pengujian & Penilaian \\
\hline 1. & Tampilan Aplikasi & sesuai \\
\hline 2. & Fungsi menu & sesuai \\
\hline 3. & Proses Terjemahan & sesuai \\
\hline
\end{tabular}




\section{Simpulan dan Rekomendasi}

Berdasarkan hasil dari Aplikasi Penerapan Natural Language Processing (NLP) Pada Kamus Kalimat Bahasa Bali ini dapat diambil kesimpulan, bahwa:

a. Aplikasi ini dapat berjalan baik pada perangkat seluler dengan sistem operasi android

b. Aplikasi ini dapat memberikan hasil terjemahan yang sesuai dengan kosakata atau ejaan dalam Bahasa Indonesia dan Bahasa Bali

c. Aplikasi kamus Bahasa Bali hanya menampilkan terjemahan dalam 1 makna, yang berarti 1 kata sama dengan 1 makna

d. Aplikasi ini dapat membantu wisatawan domestik dalam mempelajari Bahasa Bali dengan baik dan berkomunikasi dengan masyarakat Bali dengan benar

Untuk saran yang dapat diberikan adalah adanya penambahan Bahasa Inggris untuk mempermudah wisatawan asing dalam berkomunikasi dengan masyarakat Bali.

\section{Daftar Pustaka}

Desiani, Anita dan Arhami, Muhammad. (2006). Konsep Kecerdasan Buatan. Yogyakarta: Penerbit Andi

Dharwiyanti, S dan R.S. Wahono. (2003). Pengantar Unified Modelling Language (UML). Kuliah Umum IlmuKomputer.com

Nyoman Djendra. (2000). Kamus Ideal Bahasa Bali. Yayasan Dharma Pura Denpasar

Komang Trya, Resika Arhana dan Gede Sunarya. (2015). Pengembangan Aplikasi Kamus dan Penerjemahan Bahasa Indonesia-Bahasa Bali Menggunakan Metode Rule Based Berbasis Android. Kumpulan Artikel Mahasiswa Pendidikan Teknik Informatika (KARMAPATI)

Nugroho, Adi. (2010). Rekayasa Perangkat Lunak Berorientasi Objek dengan Metode USDP. Yogyakarta: Penerbit Andi

Safaat, Nazruddin. (2010). Pemrograman Aplikasi Mobile Smartphone dan Tablet Pc Berbasis Android. Bandung: Penerbit Informatika

T. Sutojo, Edi dan Vincent Suhartono. (2018). Kecerdasan Buatan. Yogyakarta: Penerbit Andi 
Tim Pusat Bahasa Departemen Pendidikan Republik Indonesia. Kamus Besar Bahasa Indonesia Daring. Online, http://pusatbahasa. kemdiknas.go.id/kbbi (diakses pada tanggal [30 April 2021)

Yuniar. (2007). Database dengan Java dan MySQL. Jakarta: Penerbit PT Elex Media Komputindo

\section{Profil Penulis}

Ayu Aprilyana Kusuma Dewi, S.Kom., M.Kom., lahir di Banyuwangi, 15 April 1993. Menempuh pendidikan S1 di Sekolah Tinggi Manajemen Informatika dan Komputer (STMIK) Denpasar dan S2 Ilmu Komputer di Universitas Pendidikan Ganesha. Saat ini penulis merupakan dosen di Politeknik Bintan Cakrawala Program Studi Pengelolaan Perhotelan. 
Ayu Aprilyana Kusuma Dewi

96 JOURNEY Volume 4 Nomor 1, Juni 2021 